\title{
Effect of Deformation on the Mechanical and Electrical Properties of Aluminum-Magnesium Alloy
}

\author{
S. O. Adeosun*, O. I. Sekunowo, S.A. Balogun, L.O. Osoba \\ Department of Metallurgical and Materials Engineering, University of Lagos, Lagos, Nigeria \\ *Corresponding Author: samsonoluropo@yahoo.com
}

\begin{abstract}
This paper presents the effect of deformation on the tensile strength, toughness, hardness and electrical resistance of aluminum 6063 alloy. Cast samples were cold rolled in the range of 0-24 percent thickness reduction and subjected to mechanical (static, dynamic) and electrical resistance tests. Results show significant improvement in hardness and electrical resistance properties of the alloy. The nature, amount and distribution of the secondary phase, $\mathrm{Mg}_{2} \mathrm{Si}$, particles precipitated within the matrix which was influenced by the extent of cold-work, are responsible for the observed behaviour. The resistance of the alloy also depends on the degree of cold work carried out prior to use.
\end{abstract}

Keywords: Cold work, tensile strength, toughness, hardness, electrical resistance.

\section{INTRODUCTION}

Pure aluminum when subjected to deformation shows an increase in ultimate tensile strength (UTS), electrical resistance and decrease in toughness and conductivity as the amount of deformation increased [1]. Aluminum 6063 alloy processed by upset forging and cold rolling at ambient temperature has shown that the UTS and hardness increase as the range of thickness reduction suffered increases from 0 to 50 percent while the ductility decreases, an indication of a low strain-hardening exponent [2]. Cold working of metal causes grain distortion and introduces imperfection in the crystal structure which affects the electrical property of the alloy. 
When cold working is combined with heat treatment, it serves the purposes of controlling final physical/mechanical properties by significantly improving structure homogenizing [3]. Physical properties such as ductility, strength and toughness are much better in a forged matrix than in the base metal due to random orientation of crystals [4]. This accounts for preference to some level of deformation on alloys in order to achieve improved mechanical properties.

There are strong interactions between the solute atoms and defects in aluminum alloys that result in structural instabilities, variation in solute profiles and changes in solute diffusion rates. Mobile dislocations are pinned by enhanced solute diffusion during tensile straining due to Portevin-Le Chatelier (P-L) effect [5]. This phenomenon appears in aluminum alloys over a range of temperatures above and below room temperature. Plastic deformation not only increases the mobility of solute atoms in aluminum alloys but also cause clustering at dislocations and these clusters act as nucleation sites for subsequent strengthening precipitates at temperatures well below the conventional aging temperatures [6]. This paper investigates the effect of varying levels of cold work on the mechanical and electrical properties of Al 6063 alloy.

\section{EXPERIMENTAL PROCEDURE}

Rectangular test samples, 350x30x12mm cast from AA6063 aluminum alloy ingot melted in an oil fired crucible furnace were used for this study. The chemical composition of the samples is presented in Table 1.

Table 1: Chemical composition of Cast 6063 aluminum alloy sample.

\begin{tabular}{|c|l|l|l|l|l|l|l|l|l|l|l|}
\hline Element & Si & Fe & Cu & Mn & Mg & Zn & Cr & Ti & Ca & Sr & Al \\
\hline \% weight & & & & & & & & & & & \\
& 0.444 & 0.202 & 0.011 & 0.013 & 0.571 & 0.006 & 0.002 & 0.008 & 0.003 & 0.003 & 98.737 \\
\hline
\end{tabular}

The cast samples were machined to $200 \times 30 \times 9 \mathrm{~mm}$ and $100 \times 25 \times 9 \mathrm{~mm}$ for cumulative and noncumulative thickness reduction respectively. The samples were then rolled at ambient temperature, $25^{\circ} \mathrm{C}$, using a four-high mill aligned with thickness reduction varying from 0 to 24 percent. The deformed samples hardness was determined using Rockwell Hardness tester type 6402 and the result is shown in Figure 1. Samples were also subjected to impact loading in a charpy-v test using standard notched impact specimens and the result illustrated in Figure 2.

Otto Wolpert Werke tensometer was used for the tensile test at the rate of $50 \mathrm{~mm} / \mathrm{min}$ and the results presented in Figure 3. Resistomat type 2319 was used to measure the samples electrical resistance while the result is illustrated in Figure 4.

Cold rolled samples were prepared for photomicrographic examination by sequential grinding using emery paper grade 80,220,320 and 600 micron in succession. Etching of the samples for 20 
seconds was done using a mixture of dilute nitric acid (68\%), hydrofluoric acid (30\%), and sodium hydroxide (2\%). Photomicrographs of samples (Plates 1-4) were taken at X200 magnifications.

\section{RESULTS AND DISCUSSION}

\subsection{Microstructure}

The as-cast sample contains clusters of $\mathrm{Mg}_{2} \mathrm{Si}$ precipitates that are well-distributed in the $\alpha$ aluminum matrix as shown on Plate 1.

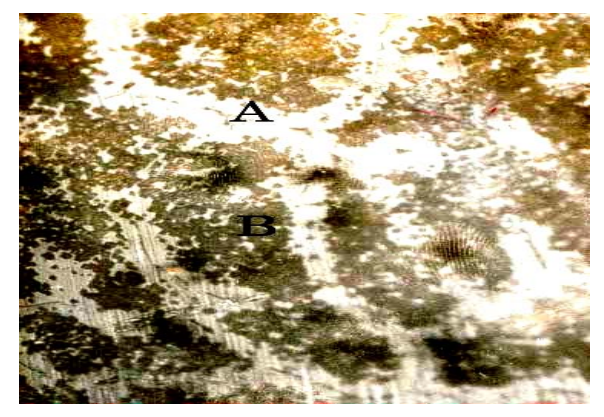

Plate 1 Microstructure of as-cast sample (A- $\alpha$-aluminum, $\mathbf{B}-\mathrm{Mg}_{2} \mathrm{Si}$ )

Rolling the sample at ambient temperature to 4 percent thickness reduction causes most of the precipitated $\mathrm{Mg}_{2} \mathrm{Si}$ to be absorbed into the matrix (Plate 2a) exhibiting thin and visible grain boundaries. There is re-precipitation of fine $\mathrm{Mg}_{2} \mathrm{Si}$ crystals that are not as coherent as those of the as-cast with reduced volume fraction at 8 percent reduction (Plate $2 b$ ).

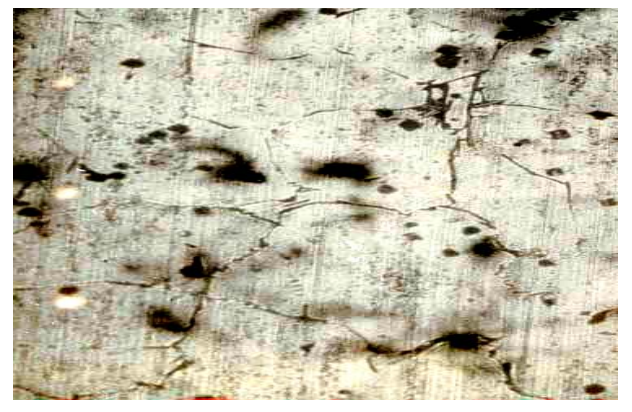

a

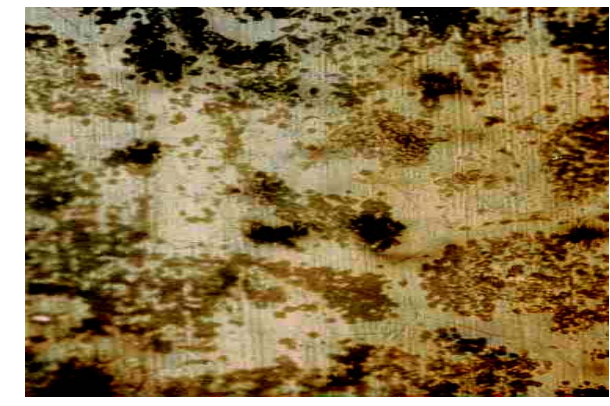

b

Plate 2 Microstructure of as-cast sample (A- $\alpha$-aluminum, B- $\mathrm{Mg}_{2} \mathrm{Si}$ )

(a) $4 \%$ reduction (b) $8 \%$ reduction

However, greater coherency of $\mathrm{Mg}_{2} \mathrm{Si}$ crystals was observed in sample subjected to 12 percent reduction with high intensity and high volume fraction when compared to the as-cast (Plate 3a). 
The intensity and coherency of crystals of $\mathrm{Mg}_{2} \mathrm{Si}$ is reduced relative to as-cast sample at 16 percent reduction (Plate $3 b$ ).

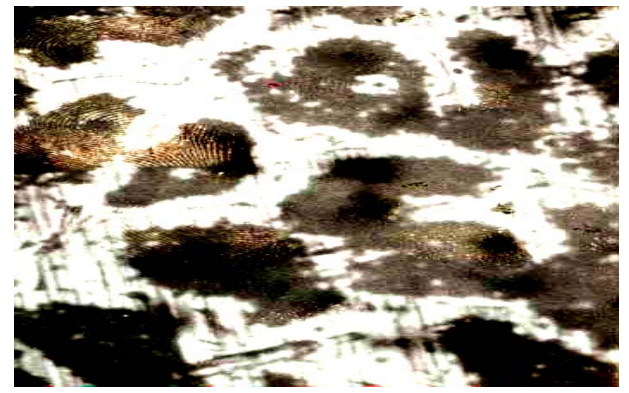

a

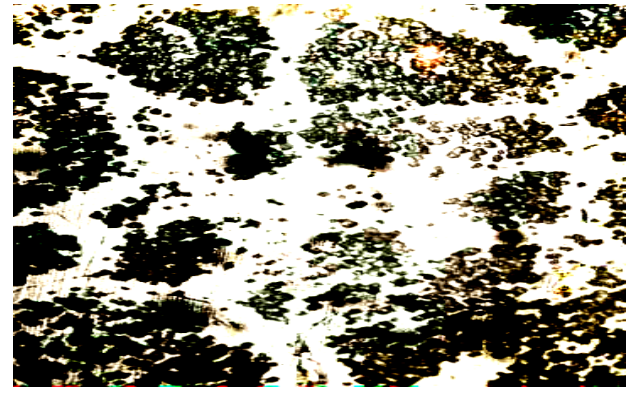

$\mathrm{b}$

Plate 3 Microstructure of as-cast sample (A- $\alpha$-aluminum, B- $\mathrm{Mg}_{2} \mathrm{Si}$ ).

(a) $12 \%$ reduction (b) $16 \%$ reduction

At 20 percent reduction in thickness, clustering and volume fraction of $\mathrm{Mg}_{2} \mathrm{Si}$ increases (Plate 4a). Processing to 24 percent reduction resulted in increase in fineness of $\mathrm{Mg}_{2} \mathrm{Si}$ crystal in the $\alpha$ aluminum matrix as shown on Plate $4 \mathrm{~b}$.

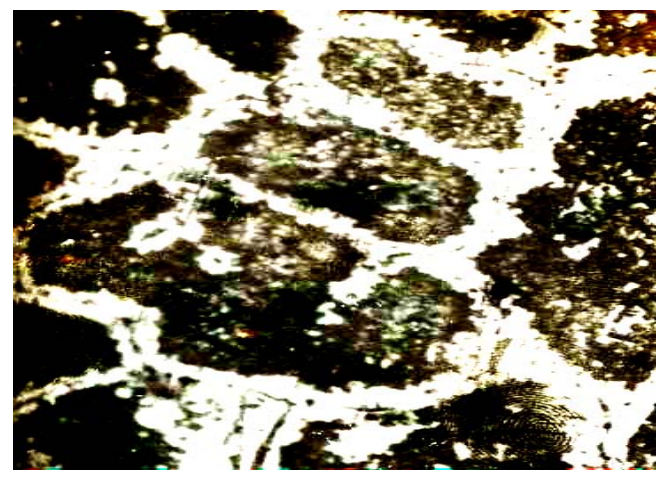

a

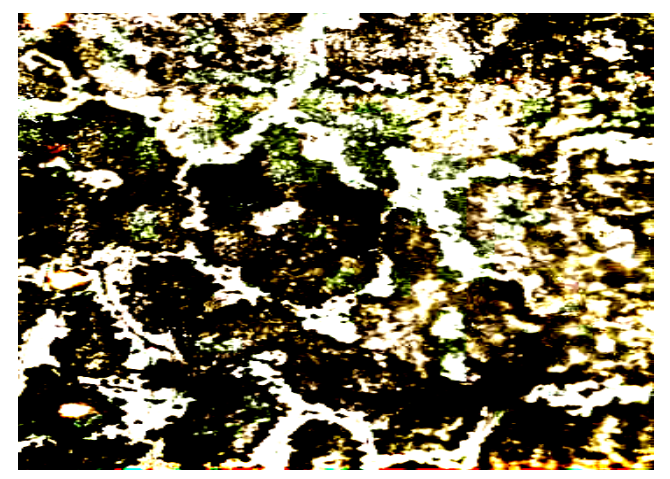

$\mathrm{b}$

Plate 4 Microstructure of as-cast sample (A- $\alpha$-aluminum, $\mathbf{B}-\mathrm{Mg}_{2} \mathrm{Si}$ )

(a) $20 \%$ reduction (b) $24 \%$ reduction

It should be noted that clustering and fineness of crystals increases both the hardness and strength of cold worked test samples. Similarly, incoherency and coarse crystals in the matrix and other solute phases promote fracture toughness of the material.

\subsection{Hardness}

The hardness of test samples increases nearly linearly initially within 0-8 percent thickness reductions whereas there is no significant increase in hardness between 8 and 14 percent thickness reduction. At 15 percent and beyond, hardness values increase gradually to the maximum, $52 \mathrm{HRE}$, at 24 percent reduction (Figure 1). The reason for this is that at 8-14 percent 
reduction, there seems to be temporary saturation in the generation of immobile dislocations as a result of reduction in the amount of $\mathrm{Mg}_{2} \mathrm{Si}$ precipitates produced.

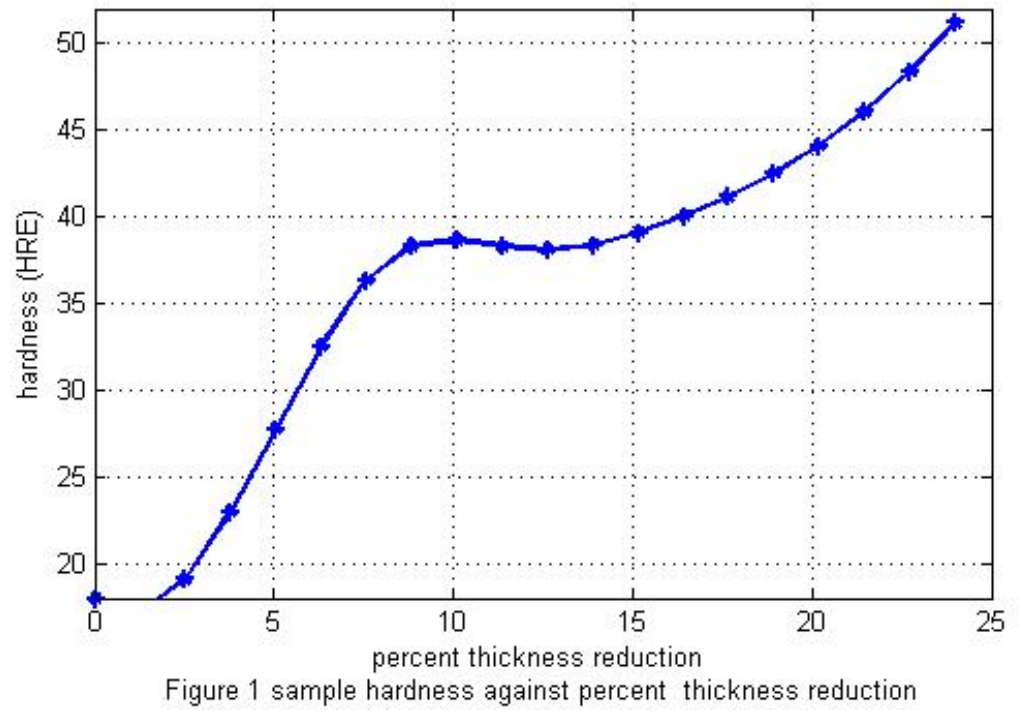

\subsection{Impact Energy}

The test samples behavior under impact loading increases from 0-5 percent thickness reduction, the maximum energy absorbed, $\sim 880 \mathrm{~J}$, occurred at 5 percent reduction (Figure 2).

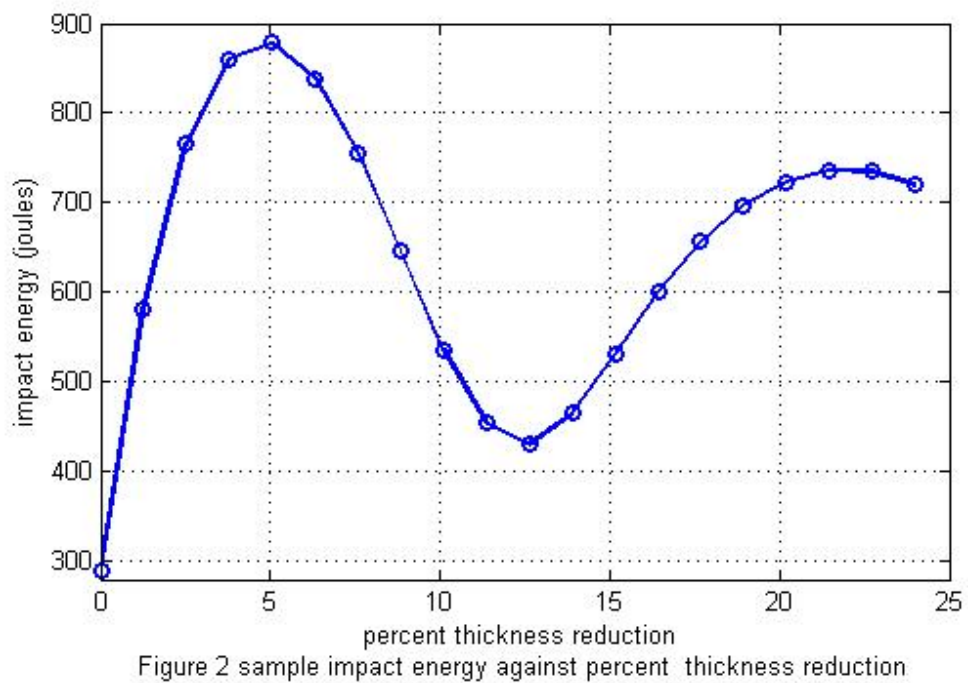

Impact energy also decreases slowly to a minimum of $425 \mathrm{~J}$ at about 13 percent reduction. However, beyond this level of reduction, impact energy increases gradually to $730 \mathrm{~J}$ with a tendency to decrease at higher reduction. The minimum of $425 \mathrm{~J}$ occur at 13 percent reduction in the domain of immobile dislocation generation saturation. The toughness of a material reduces as the level of cold work increases [7]. 
This may be explained using the 16 percent cold work microstructure (Plate $3 \mathrm{~b}$ ) in which the presence of the second phase precipitates, $\mathrm{Mg}_{2} \mathrm{Si}$, reduces progressively at grain boundaries corresponding to test sample's percent thickness reduction.

\subsection{Tensile Strength}

The effect of thickness of samples reduction during deformation at ambient temperature on the UTS is sinusoidal (Figure 3). The peak tensile strength, $142 \mathrm{MPa}$, occurred at 17 percent reduction while the minimum of $100 \mathrm{MPa}$ was obtained at 23 percent reduction. The non linearity of the curve at 16 percent cold work is as a result of precipitates of second phase intermetallic, $\mathrm{Mg}_{2} \mathrm{Si}$, which were more pronounced than for other levels of cold work (Plate 2a, 2b, 3a, 4a and 4b). According to Li and Ghosh [8], uniaxial tensile test usually serve as a major screening for ranking relative strength of alloy deformation behaviour. Hence, there are more clustering of the second phase crystals within the matrix in tandem with percent thickness reduction sequence.

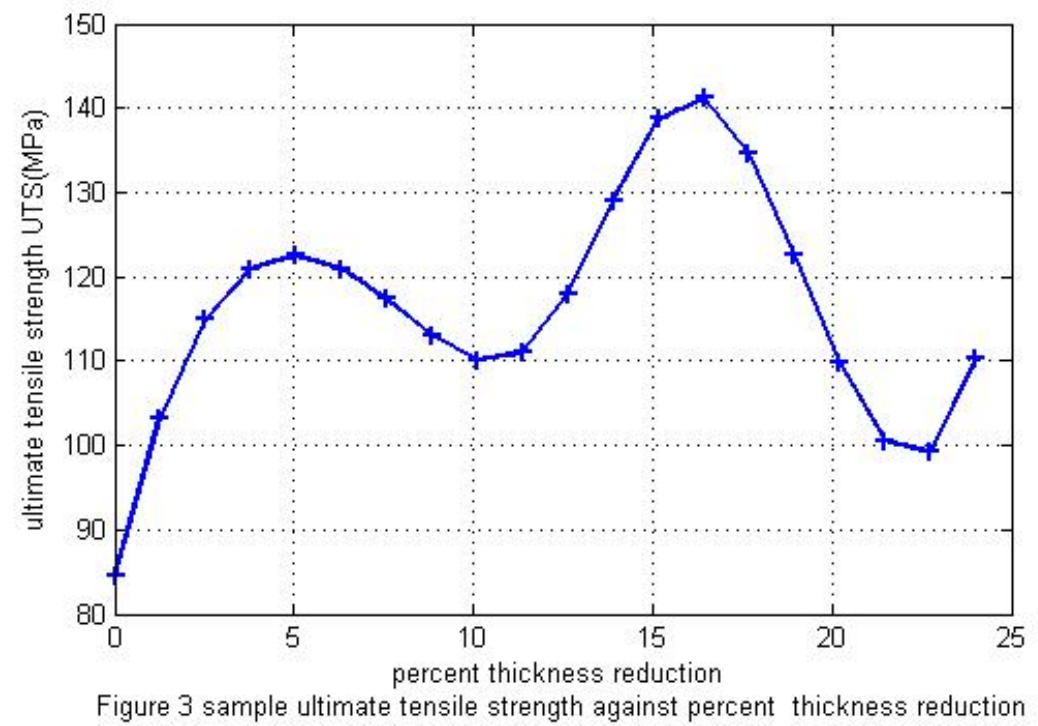

\subsection{Electrical Resistance}

The electrical resistance of test samples after deformation shows a near linear relationship with thickness reduction for reduction in the ranges from 5-24 percent (non-cumulative). However, the increase in resistance is rather slow as reduction increases (Figure 4). 


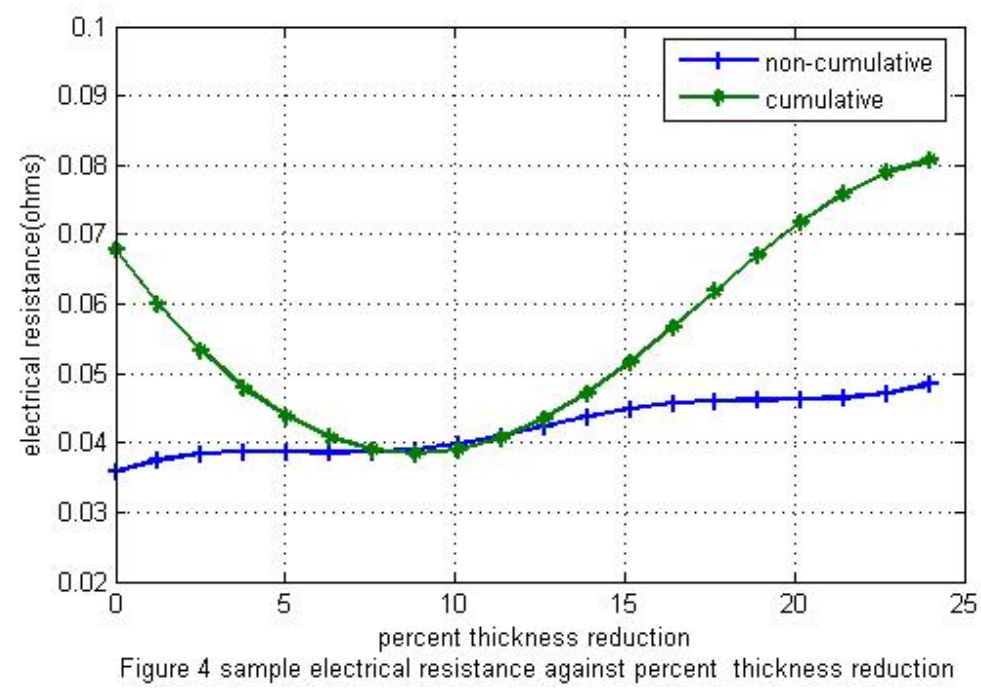

In the as-cast state the resistance is $\sim 0.07 \Omega$ but rises steadily to a maximum value of $0.08 \Omega$ at 24 percent reduction. Graphical representation of the non-cumulative and cumulative test result shows that the electrical resistance of aluminum alloy 6063 increase with increased cold work. This is because the resistance of a material does not only depend on the length but also on imperfections such as the distribution of second phase crystals and the volume fraction of matrix constituents in the material [9].

\section{CONCLUSION}

The study conducted revealed that cold working of 6063 aluminum alloy impacts significant effects on its mechanical and electrical properties. It has been shown that hardness and resistance increased from 0 to 24 percent thickness reduction. Substantial improvement in toughness, strength, hardness and low resistance to current flow is feasible at a thickness reduction in the neighborhood of 5 percent. At this level of reduction, most of the precipitated $\mathrm{Mg}_{2} \mathrm{Si}$ crystals are absorbed into the matrix and there is increase in homogeneity of solution as it becomes more isotropic. Though the degree of deformation has significant effect on the conductivity of the alloy however, this will be impaired if the material is made to suffer severe deformation.

\section{REFERENCE}

[1] Van Lanker. (1967), "Metallurgy of aluminum Alloys." William Clones and Sons Ltd. pp. 236-248.

[2] Balogun, S., Esezobor, D. and Adeosun, S. (2007), "Effects of Deformation Processing on the Mechanical Properties of Aluminum Alloy 6063." Metallurgical and Materials Transactions A, Volume 38, Number 7, pp. 1570-1574(5). 
[3] Abdulhaqq .A. Hamid, P., Ghosh, S., Jain, O. and Subrata, R. (2005), "Processing, Microstructure and Mechanical Properties of Cast in-situ $\mathrm{Al}(\mathrm{Mg}, \mathrm{Mn})-\mathrm{Al}_{2} \mathrm{O}_{3}\left(\mathrm{MnO}_{2}\right)$ Composites." Metallurgical and Materials Transactions A, Vol. 36A, pp 221.

[4] Roy, N., Samuel, A. and Samuel, F. (1996), Metallurgical and Materials Transactions, Vol. 27A, pp. 415-429.

[5] Lassance, D., Schmitz, M., Delannay F. and Pardoen, T. (2002), "Linking Microstructure and High Temperature Ductility in Aluminum alloys AA6xxx." Seminar paper available online at: www.hallf.kth.se/forskning/ecf15/ECF-proceedings/Lassance.

[6] Valiev, R., Krashkov, N. and Tsenev, K. (1991), "Plastic Deformation of Alloys with Submicron-grained Structure." Materials Science and Engineering A, Vol.153, Issue 3, pp. 172-196.

[7] Doege, E. and Droder, K. (2001), "Sheet Metal Forming of Magnesium Wrought AlloysFormability and Process Technology." Materials Science and Engineering A, Vol. 27B, Issue 3, pp. 89-102.

[8] Li, D. and Ghosh, A. (2003), "Tensile Deformation Behaviour of Aluminium Alloys at Warm Forming Temperatures." Materials Science and Engineering A, Vol. 352, Issue 1-2, pp. 279286.

[9] Miller, W., Zhuang, L., Botterma, J. and Wtterbrood, A. (2000), "Recent Development in Aluminium Alloys for the Automobile Industry." Journal of Materials Science, Vol. 273, Issue 1-2, pp. 204-215. 